\title{
A real 3D measurement technique for the tibial slope: differentiation between different articular surfaces and comparison to radiographic slope measurement
}

\author{
Armando Hoch ${ }^{1 *}$ (D, Lukas Jud ${ }^{1}$, Tabitha Roth², Lazaros Vlachopoulos ${ }^{1}$, Philipp Fürnstahl ${ }^{2}$ and Sandro F. Fucentese ${ }^{1}$
}

\begin{abstract}
Background: The tibial slope plays an important role in knee surgery. However, standard radiographic measurement techniques have a low reproducibility and do not allow differentiation between medial and lateral articular surfaces. Despite availability of three-dimensional imaging, so far, no real 3D measurement technique was introduced and compared to radiographic measurement, which were the purposes of this study.

Methods: Computed tomography scans of 54 knees in 51 patients (41 males and 10 females) with a mean age of 46 years (range 22-67 years) were included. A novel 3D measurement technique was applied by two readers to measure the tibial slope of medial and lateral tibial plateau and rim. A statistical analysis was conducted to determine the intraclass correlation coefficient (ICC) for the new technique and compare it to a standard radiographic measurement.

Results: The mean 3D tibial slope for the medial plateau and rim was $7.4^{\circ}$ and $7.6^{\circ}$, for the lateral plateau and rim $7.5^{\circ}$ and $8.1^{\circ}$, respectively. The mean radiographic slope was $6.0^{\circ}$. Statistical analysis showed an ICC between both readers of $0.909,0.987,0.918,0.893$, for the $3 \mathrm{D}$ measurement of medial plateau, medial rim, lateral plateau and lateral rim, respectively, whereas the radiographic technique showed an ICC of 0.733 .

Conclusions: The proposed novel measurement technique shows a high intraclass agreement and offers an applicable opportunity to assess the tibial slope three-dimensionally. Furthermore, the medial and lateral articular surfaces can be measured separately and one can differentiate the slope from the plateau and from the rim. As three-dimensional planning becomes successively more important, our measurement technique might deliver a useful supplement to the standard radiographic assessment in slope related knee surgery.
\end{abstract}

Level of evidence: Level III, diagnostic study.

Keywords: Tibial slope, 3D measurement, Articular surface

* Correspondence: armando.hoch@balgrist.ch

'Department of Orthopaedics, Balgrist University Hospital, Forchstrasse 340, 8008 Zurich, Switzerland

Full list of author information is available at the end of the article

C C The Author(s). 2020 Open Access This article is licensed under a Creative Commons Attribution 4.0 International License, which permits use, sharing, adaptation, distribution and reproduction in any medium or format, as long as you give appropriate credit to the original author(s) and the source, provide a link to the Creative Commons licence, and indicate if changes were made. The images or other third party material in this article are included in the article's Creative Commons licence, unless indicated otherwise in a credit line to the material. If material is not included in the article's Creative Commons licence and your intended use is not permitted by statutory regulation or exceeds the permitted use, you will need to obtain permission directly from the copyright holder. To view a copy of this licence, visit http://creativecommons.org/licenses/by/4.0/. The Creative Commons Public Domain Dedication waiver (http://creativecommons.org/publicdomain/zero/1.0/) applies to the data made available in this article, unless otherwise stated in a credit line to the data. 


\section{Highlights}

- The tibial slope plays an important role in knee surgery planning

- Available measurement techniques show a low intraclass correlation

- So far, no real 3D measurement technique was introduced

- Our novel 3D measurement technique showed an excellent intraclass correlation

\section{Background}

The inclination of the proximal articular surface of the tibia was first described and introduced as tibial slope in an anatomical study in 1951 [1]. As total knee replacement was gaining popularity, the importance of the tibial slope in sagittal plane balancing was recognized [2-4]. The tibial slope was depicted as an important factor influencing postoperative knee flexion and stability after total and unicompartmental knee replacement and various recommendations were made to restore or increase the native slope to optimize range of motion [5-10]. Furthermore, an increased tibial slope was recognized as a risk factor for anterior cruciate ligament (ACL) rupture in native knees [1114], whereas a decreased tibial slope could be identified as a risk factor for posterior cruciate ligament (PCL) injury [15]. These findings were used to reduce the forces acting on ACL-grafts and to address instability in ACL-deficient knees by reducing the tibial slope when performing a high tibial osteotomy (HTO) [15-18].

Measurement of the tibial slope has been discussed controversially. Various two-dimensional measurement techniques in lateral radiographs of the knee are available [19-22]. There is lack of clarity regarding the accuracy of these measurements: On the one hand the anatomical tibial axis cannot reliably be determined on most lateral knee radiographs and, on the other hand, one cannot differentiate between the medial and the lateral articular surface. These factors lead to an unsatisfying intraclass correlation [23-26]. Therefore, different three-dimensional techniques have been proposed [2532]. To our knowledge, there is no measurement technique which considers the three-dimensional anatomical tibial axis and the volumetric constitution of the proximal tibia to differentiate between medial and lateral plateau and rim in a three-dimensional model.

The first purpose of this study was to introduce such a technique. Furthermore, no comparison between threedimensionally assessed tibial slope and standard radiographic assessment has been conducted, which was the second purpose of our study. The hypothesis was that such a 3D technique can be introduced for the measurement of the tibial slope and that it has a high robustness, superior to the standard radiographic measurement.

\section{Methods}

\section{Patient selection}

We retrospectively identified 82 consecutive patients who received a computed tomography (CT) scan of one or both native knees, including the proximal $15 \mathrm{~cm}$ of the tibia. In all patients a lateral view radiograph of the investigated knees was available. All CT scans were performed at our institution from 11/2016 to 01/2019. These patients were all scheduled for an osteotomy navigated by patient specific instruments for different reasons. Nineteen patients who underwent a correction of the tibial slope were excluded subsequently in order to obtain a collective without slope-related problems. Two patients were additionally excluded because a sloperelated problem could not be ruled out. Two patients with a posttraumatic status, two patients with prior osseous knee surgery, five patients with dysplasia and one patient with osteogenesis imperfecta were excluded from this study to exclude pathologically altered bony anatomy. Finally, we included CT scans and radiographs of 54 knees from 51 patients (41 males and 10 females) with a mean age of 46 years (range 22-67 years) and a mean BMI of $30.4 \mathrm{~kg} / \mathrm{m}^{2}$ (range 20.4-41.2 $\mathrm{kg} / \mathrm{m}^{2}$ ). They were all planned for HTO for unicompartmental osteoarthritis, whereas the radiographic degree of osteoarthritis was mild (Kellgren and Lawrence grade I or II) in all cases. The local ethical committee approved this study (Zurich Cantonal Ethics Commission, 201802242) and all patients gave their informed consent for the use of their data for research purposes.

\section{CT examinations}

All CT scans were performed at our institution, using Siemens Definition $\mathrm{AS}^{\ominus}$ or Somatom Edge $\mathrm{CT}^{\circ}$ scanners. Slice thickness was $1.0 \mathrm{~mm}$ with an in-plane resolution $(x-y)$ of $0.4 \times 0.4 \mathrm{~mm}$.

The CT scans were segmented using the global thresholding and region growing functionality of a standard segmentation software (Mimics Medical, Materialise NV, Leuven, Belgium) in order to generate 3D bone models [33-35].

\section{D slope measurement technique}

Four different parts of the articular surface of the 3D bone models were subsequently marked with a brushing tool (3-matic Medical, Materialise NV, Leuven, Belgium): The medial plateau, the medial rim, the lateral plateau and the lateral rim. These parts are depicted in Fig. 1 . They were brushed by the respective investigator. The rim was defined as the outermost, elevated portion of the joint surface. The plateau was defined as the concavity of the articular surface typically opposite the femoral condyle. The intercondylar region was not integrated into the brushing. Using our in-house 
a)

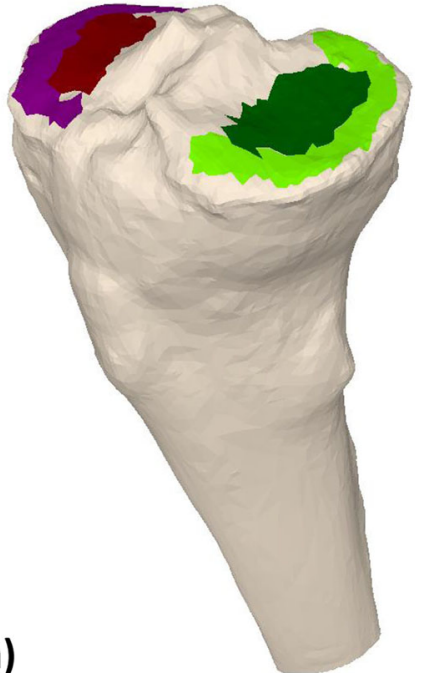

b)

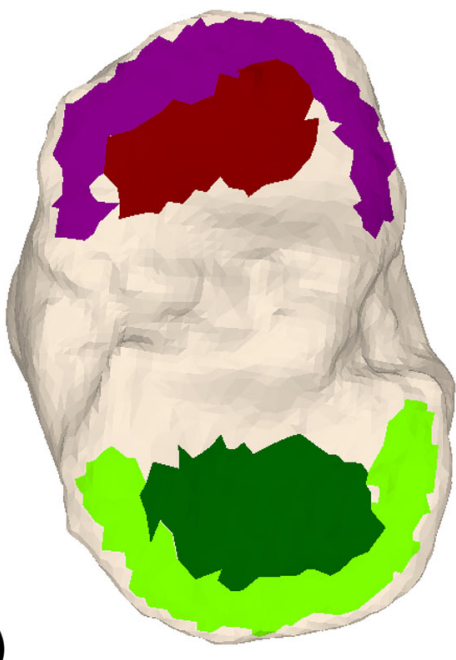

Fig. 1 Four different brushed parts of the articular surface: Medial plateau (dark green), medial rim (bright green), lateral plateau (dark red), lateral rim (purple) in relation to the proximal tibia (beige) in a view from superomedial a) and above b)

planning software (CASPA, Balgrist CARD, Zurich, Switzerland), principal component analysis (PCA) was applied to each of the four surface models, creating a plane with a minimal squared distance to each of the points of the surface models [36] (Fig. 2).

For the anatomical axis, an axial cross section of the tibial shaft was automatically generated $15 \mathrm{~cm}$ distal from the articular knee surface. This procedure was repeated in $5 \mathrm{~mm}$ steps proximal from the first cross section, until the cross-section area exceeded a threshold (1.6-fold of the first cross section area). The anatomical axis was then fitted using a least square approach, minimizing the distance to the center points of all cross sections (Fig. 3) [36]. The tibial slope was defined as the angle between the anatomical axis and the tibial slope normal, projected to the sagittal plane. The sagittal plane was defined according to a previously published method [37]. This was done for all aforementioned four articular surface parts. These calculations were made using
MATLAB R 2019a (The MathWorks Inc., Natick, Massachusetts, USA).

On conventional 2D radiographs, we assessed the posterior tibial slope, using the posterior tibial cortex line, which is, to our knowledge, the most frequently applied technique (Fig. 4) [19-22]. The slope was measured as the angle between a line drawn along the posterior tibial cortex and a line adjacent to the horizontally arranged zone of highest radiodensity on the uppermost part of the tibial head. All measurements were performed by two readers (A. H., L. J.).

\section{Statistical analysis}

All data were documented with the REDCap software (Research Electronic Data Capture, Vanderbilt University, Nashville, Tennessee, USA). Statistical analyses, conducted with SPSS (IBM SPSS Statistics 25, IBM, Armonk, New York, USA), were used to provide descriptive data as mean and standard deviation (SD). The

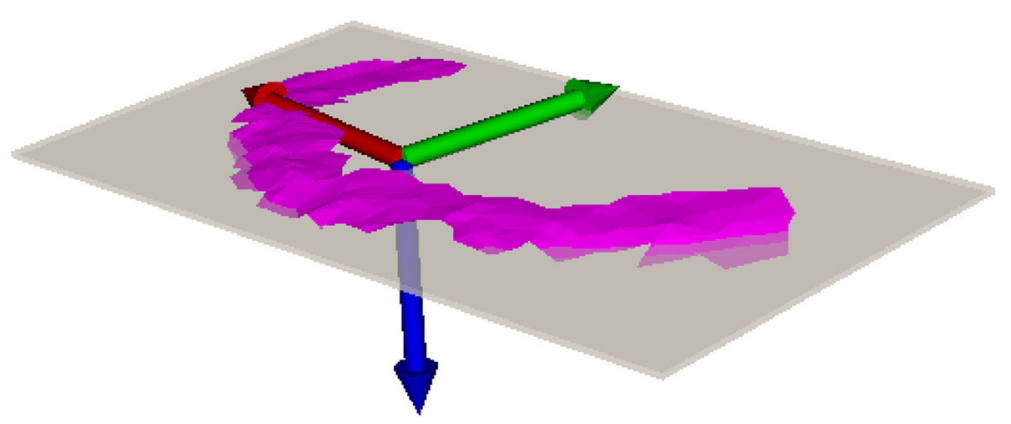

Fig. 2 Example for a brush of a lateral rim of the tibia plateau (pink) with the plane (transparent grey) with a minimal squared distance to each of the points of the surface model. Additionally the coordinate system defining the tibial slope normal (z-axis, blue) of this specific model. 


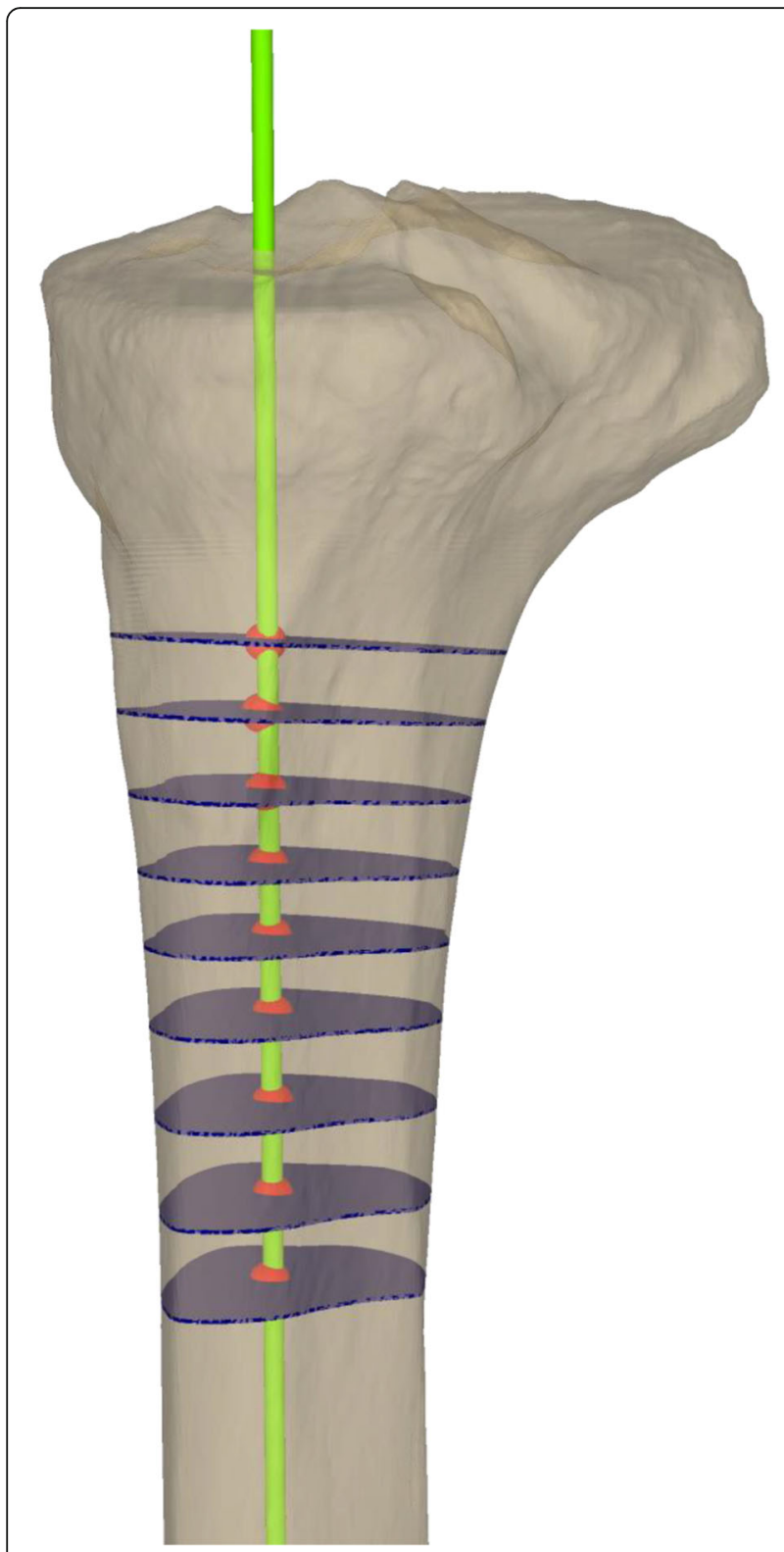

Fig. 3 Anatomical axis (bright green) of the tibia (transparent beige), defined by the center points (red) of all cross sections (transparent dark blue)

intraclass correlation coefficients for the different parameters were calculated based on a two-way random effects model assessing absolute agreement of single measures between readers.

\section{Results}

The mean 3D tibial slope for the medial plateau and rim was $7.4^{\circ}$ and $7.6^{\circ}$, for the lateral plateau and rim $7.5^{\circ}$ and $8.1^{\circ}$, respectively. The mean radiographic slope was $6.0^{\circ}$. Statistical analysis showed an ICC between both readers of $0.909,0.987,0.918,0.893$, for the 3D measurement of medial plateau, medial rim, lateral plateau and lateral

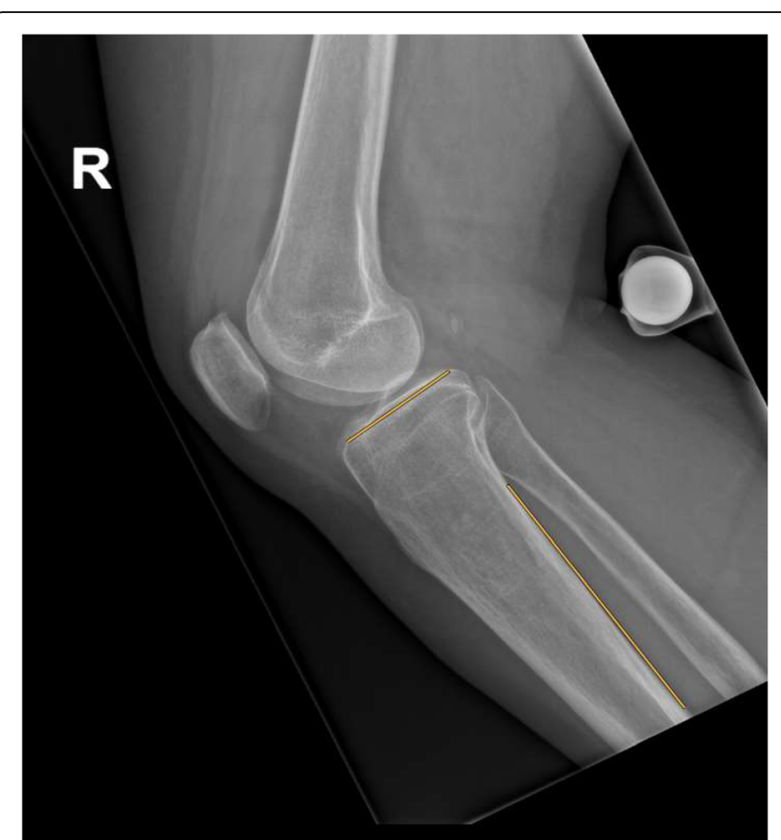

Fig. 4 Lateral view radiograph of a right knee with the two lines (orange) for conventional measurement of the posterior tibial slope

rim, respectively, whereas the radiographic technique showed an ICC of 0.733 (Table 1). There were no significant differences between the medial and lateral compartments, nor between the rim and plateau.

\section{Discussion}

A measurement technique which considers the threedimensional anatomical tibial axis and the volumetric constitution of the proximal tibia to differentiate between medial and lateral plateau and rim in a threedimensional model is lacking. The purposes of our study were the introduction of such a technique and its comparison with standard radiographic measurement techniques.

The most important finding of this study is that the proposed novel three-dimensional measurement technique showed a mainly excellent intraclass correlation [38]. Furthermore, the technique is capable of assessing the slope for the lateral and medial plateau and rim separately. We think this is of high importance since from a kinematic point of view the plateau might play a central role as it - and not the rim - contains the weight bearing area [39-41]. Therefore, we propose, that for evaluation of the tibial slope, values derived from the plateaus should be used. In addition, it could be used in special situations, where a differentiation is needed (e.g. posttraumatic situations after tibial plateau fractures or for intra-articular corrective osteotomies). As expected, the intraclass correlation for the 2D measurement technique was low and therefore this technique was clearly inferior 
Table 1 Slope measurements and Intraclass correlation coefficients

\begin{tabular}{|c|c|c|c|c|c|}
\hline reader & medial plateau & medial rim & lateral plateau & lateral rim & radiograph (PTS) \\
\hline \multirow[t]{2}{*}{1} & $7.5^{\circ}$ & $7.6^{\circ}$ & $7.7^{\circ}$ & $8.2^{\circ}$ & $6.0^{\circ}$ \\
\hline & SD $4.72^{\circ}$, range $-2.0^{\circ}-17.3^{\circ}$ & SD $3.91^{\circ}$, range $-1.7^{\circ}-14.6^{\circ}$ & SD $4.46^{\circ}$, range $-2.3^{\circ}-15.1^{\circ}$ & SD $2.98^{\circ}$, range $2.2^{\circ}-14.6^{\circ}$ & SD $2.90^{\circ}$, range $-0.7^{\circ}-11.9^{\circ}$ \\
\hline \multirow[t]{2}{*}{2} & $7.3^{\circ}$ & $7.6^{\circ}$ & $7.4^{\circ}$ & $8.0^{\circ}$ & $5.9^{\circ}$ \\
\hline & SD $3.45^{\circ}$, range $-0.9^{\circ}-15.0^{\circ}$ & SD $3.80^{\circ}$, range $-1.1^{\circ}-14.8^{\circ}$ & SD $3.45^{\circ}$, range $-0.1^{\circ}-13.2^{\circ}$ & SD $3.09^{\circ}$, range $1.1^{\circ}-14.7^{\circ}$ & SD $3.00^{\circ}$, range $-4.1^{\circ}-11.8^{\circ}$ \\
\hline \multirow[t]{2}{*}{ ICC } & 0.909 & 0.987 & 0.918 & 0.893 & 0.733 \\
\hline & $95 \%$ Cl, $0.849 ; 0.946$ & $95 \%$ Cl, $0.977 ; 0.992$ & $95 \%$ Cl, $0.860 ; 0.952$ & $95 \%$ Cl, $0.823 ; 0.936$ & $95 \% \mathrm{Cl}, 0.581 ; 0.836$ \\
\hline
\end{tabular}

PTS Posterior tibial slope, SD Standard deviation, CI Confidence interval, ICC Intraclass correlation coefficient

to the 3D measurement technique. Although not in the focus of our study, we have compared the different 3D parameters with the $2 \mathrm{D}$ measurement results. The interclass correlation coefficients comparing 3D parameters with standard radiographic measurement of the posterior tibial slope were low. The radiographic measurement doesn't seem to be reflected by one of the different three-dimensional slope measurements. This is in line with the assumption that neither medial nor lateral structures can safely be differentiated in lateral knee radiographs.

Since three-dimensional imaging has become standard in preoperative assessment, several studies were conducted to describe techniques for tibial slope measurements based on these images. Hudek et al. used sagittal MR examinations to measure the medial and the lateral tibial slope separately [25]. They defined the anatomical tibial axis in one single MR slice through the center of the knee in which only the very proximal tibia was available. For the slope measurement a tangent connecting the uppermost anterior and posterior cortex edges of the medial and lateral plateau was drawn. Their proposed assessment of the tibial axis seems questionable because it is dependent from the length of the tibia in the determined sagittal plane. Furthermore, only the rim, and as such not the weight bearing part of the knee, was used for slope determination. In their study intraclass correlation coefficient was 0.77 .

Haddad et al. investigated the tibial slope in a larger collective of 143 patients with a new technique for slope assessment in MRI [26]. They also used single crosssectional slices to determine the tibial slope but in a more reproducible fashion compared to Hudek et al. which consolidated in a higher intraclass correlation coefficient of 0.84 . Saxena et al. published an additional measurement technique in 2016 [27]. They were able to evade the problem of the dependency of the sagittal reconstruction described in the work of Hudek et al. by coordinating axial, coronal and sagittal plane. Nevertheless, again the uppermost cortical points were chosen to determinate the slope. The evaluation of reproducibility was not evaluated in their study and therefore an intraclass correlation coefficient was not provided.
Amerinatanzi et al. published the first technique using points on the surface of a proximal tibia model based on an MRI [29]. They used multiple points in $2 \mathrm{~mm}$ increment on the medial and lateral rim for tibial slope calculation. The intraclass correlation coefficient was 0.909 for the medial and 0.968 for the lateral rim. For calculation of tibial anatomical axis, they used the most proximal two centimeters of the tibia. Their measurements were made on one single individual. One year later an automated version of the same measurement technique was published by the same authors [30]. This time they investigated their technique on nine individuals. Furthermore, they made an adaption that provided information about the slope in areas of kinematic interest, which was defined by the authors as the deepest depressions of the medial and lateral proximal tibial surfaces. Within these areas, again projected points on the rim were used for measurement. Amirtharaj et al. proposed another technique based on CT scans [31]. Their technique contained an automated measurement also using multiple points in 3 degrees increment around a center in the middle of the tibial plateau situated on the uppermost part of the rim. Three cadaveric knees were used. Ho et al. used data from $100 \mathrm{CT}$ scans to develop a 3D measurement technique [32]. For slope measurement the lateral and the medial articular surfaces of the proximal tibia containing plateau and rim were used. Nevertheless, only a smaller part of the collective was measured by a second reader and no intraclass correlation coefficient for the whole collective was provided. None of the mentioned studies compared the threedimensional slope to standard radiographic slopes.

A limitation of our study is the study population of patients who were designated for a high tibial osteotomy which could suggest a preexisting bony condition. An influence of this condition on the tibial slope is conceptually unlikely. Patients with severe bony defects were not found in our collective, as they would not qualify for HTO. Furthermore, a preexisting pathological slope in our collective as reason for unicompartmental osteoarthritis cannot be excluded but is highly unlikely since the collective shows a mean slope comparable to previous data $[4,21,23,24]$. 
Another limitation is the fact that CT scans are not a standard diagnostic tool even in potentially slope related problems and segmentation is time-consuming and requires specific knowledge which is not always accessible. Since CT scans are progressively improved in terms of dose reduction and our measurement technique could be implemented in a computer program, a clinically suitable solution is imaginable [42]. Furthermore, MRI technique is also evolving and new protocols that make segmentation easier will be available. Our method could then also be applied to models derived from MRI data. However, 3D planning and the use of patient specific instruments has gained importance in the last decade and with further development we believe that it will be even more used in the future [43]. Intra-reader ICC was not performed due to the highly standardized definition of the surfaces and that the mainly automatized measurement procedure.

\section{Conclusion}

The proposed novel measurement technique shows a high intraclass agreement and offers an applicable opportunity to assess the tibial slope three-dimensionally. Furthermore, the medial and lateral articular surfaces can be measured separately and one can differentiate the slope from the plateau and from the rim. As threedimensional planning becomes successively more important, our measurement technique might deliver a useful supplement to the standard radiographic assessment in slope related knee surgery.

\section{Acknowledgments}

This work is part of the LEDECO project supported by the SNF Swiss National Science Foundation (Grant Number: 320030_182352).

\section{Authors' contributions}

A. H.: Conceptualization, Methodology, Investigation, Writing - Original Draft, Visualization, L. J.: Methodology, Investigation, T. R.: Methodology, Software, Formal analysis, Visualization, L. V.: Conceptualization, Methodology, Supervision, P. F.: Resources, Supervision, Writing - Review and Editing, S. F. F.: Resources, Supervision, Writing - Review and Editing. The author (s) read and approved the final manuscript.

\section{Funding}

This work is part of the LEDECO project supported by the SNF Swiss National Science Foundation (Grant Number: 320030_182352).

\section{Availability of data and materials}

The datasets used and analyzed during the current study are available from the corresponding author on reasonable request.

\section{Ethics approval and consent to participate}

The local ethical committee approved this study (Zurich Cantonal Ethics Commission, 2018-02242). All patients gave their informed consent for their participation in and the publication of this study.

\section{Consent for publication}

All authors read the final version of this manuscript and gave their consent for publication.

\section{Competing interests}

The authors declare that they have no conflict of interest.

\section{Author details}

'Department of Orthopaedics, Balgrist University Hospital, Forchstrasse 340, 8008 Zurich, Switzerland. ${ }^{2}$ Research in Orthopaedic Computer Science, Balgrist University Hospital, University of Zurich, Zurich, Switzerland.

Received: 2 June 2020 Accepted: 18 September 2020

Published online: 26 September 2020

\section{References}

1. Titze A. Variations in the slope of the proximal articular surface of the tibia. Z Orthop Ihre Grenzgeb. 1951;80(3):436-44.

2. Ewald FC, Jacobs MA, Miegel RE, Walker PS, Poss R, Sledge CB. Kinematic total knee replacement. J Bone Joint Surg Am. 1984;66(7):1032-40.

3. Whiteside LA, Amador DD. The effect of posterior tibial slope on knee stability after Ortholoc total knee arthroplasty. J Arthroplast. 1988;3(Suppl): S51-7.

4. Matsuda S, Miura H, Nagamine R, Urabe K, Ikenoue T, Okazaki K, et al. Posterior tibial slope in the normal and varus knee. Am J Knee Surg. 1999; 12(3):165-8

5. Walker PS, Garg A. Range of motion in total knee arthroplasty. A computer analysis. Clin Orthop Relat Res. 1991;(262):227-35.

6. Singh G, Tan JH, Sng BY, Awiszus F, Lohmann CH, Nathan SS. Restoring the anatomical tibial slope and limb axis may maximise post-operative flexion in posterior-stabilised total knee replacements. Bone Joint J. 2013;95-B(10): 1354-8.

7. Chambers AW, Wood AR, Kosmopoulos V, Sanchez HB, Wagner RA. Effect of posterior Tibial slope on flexion and anterior-posterior Tibial translation in posterior cruciate-retaining Total knee Arthroplasty. J Arthroplast. 2016;31(1): 103-6.

8. Kang KT, Kwon SK, Son J, Kwon OR, Lee JS, Koh YG. The increase in posterior tibial slope provides a positive biomechanical effect in posteriorstabilized total knee arthroplasty. Knee Surg Sports Traumatol Arthrosc. 2018;26(10):3188-95.

9. Takatsu T, Itokazu M, Shimizu K, Brown TD. The function of posterior tilt of the tibial component following posterior cruciate ligament-retaining total knee arthroplasty. Bull Hosp Jt Dis. 1998;57(4):195-201.

10. Suzuki T, Ryu K, Kojima K, Oikawa H, Saito S, Nagaoka M. The effect of posterior Tibial slope on joint gap and range of knee motion in Mobilebearing Unicompartmental knee Arthroplasty. J Arthroplast. 2019.

11. Dejour H, Bonnin M, et al. J Bone Joint Surg Br. 1994;76(5):745-9.

12. Griffin $L Y$, Albohm MJ, Arendt EA, Bahr R, Beynnon BD, Demaio M, et al. Understanding and preventing noncontact anterior cruciate ligament injuries: a review of the Hunt Valley II meeting, January 2005. Am J Sports Med. 2006;34(9):1512-32.

13. Hashemi J, Chandrashekar N, Mansouri H, Gill B, Slauterbeck JR, Schutt RC Jr, et al. Shallow medial tibial plateau and steep medial and lateral tibial slopes: new risk factors for anterior cruciate ligament injuries. Am J Sports Med. 2010;38(1):54-62

14. Brandon ML, Haynes PT, Bonamo JR, Flynn MI, Barrett GR, Sherman MF. The association between posterior-inferior tibial slope and anterior cruciate ligament insufficiency. Arthroscopy. 2006;22(8):894-9.

15. Bernhardson AS, DePhillipo NN, Daney BT, Kennedy MI, Aman ZS, LaPrade RF. Posterior Tibial slope and risk of posterior cruciate ligament injury. Am J Sports Med. 2019:47(2):312-7.

16. Badhe NP, Forster IW. High tibial osteotomy in knee instability: the rationale of treatment and early results. Knee Surg Sports Traumatol Arthrosc. 2002; 10(1):38-43

17. Imhoff FB, Mehl J, Comer BJ, Obopilwe E, Cote MP, Feucht MJ, et al. Slopereducing tibial osteotomy decreases $\mathrm{ACL}$-graft forces and anterior tibial translation under axial load. Knee Surg Sports Traumatol Arthrosc. 2019; 27(10):3381-9.

18. Zaffagnini S, Bonanzinga T, Grassi A, Marcheggiani Muccioli GM, Musiani C, Raggi F, et al. Combined ACL reconstruction and closing-wedge HTO for varus angulated ACL-deficient knees. Knee Surg Sports Traumatol Arthrosc. 2013;21(4):934-41.

19. Genin P, Weill G, Julliard R. The tibial slope. Proposal for a measurement method. J Radiol. 1993;74(1):27-33.

20. Paley D, Maar DC, Herzenberg JE. New concepts in high tibial osteotomy for medial compartment osteoarthritis. Orthop Clin North Am. 1994;25(3): 483-98. 
21. Brazier J, Migaud H, Gougeon F, Cotten A, Fontaine C, Duquennoy A. Evaluation of methods for radiographic measurement of the tibial slope. A study of 83 healthy knees. Rev Chir Orthop Reparatrice Appar Mot. 1996; 82(3):195-200

22. Gunes T, Sen C, Erdem M. Tibial slope and high tibial osteotomy using the circular external fixator. Knee Surg Sports Traumatol Arthrosc. 2007;15(2): $192-8$.

23. Utzschneider S, Goettinger M, Weber P, Horng A, Glaser C, Jansson V, et al. Development and validation of a new method for the radiologic measurement of the tibial slope. Knee Surg Sports Traumatol Arthrosc. 2011; 19(10):1643-8.

24. Faschingbauer M, Sgroi M, Juchems M, Reichel H, Kappe T. Can the tibial slope be measured on lateral knee radiographs? Knee Surg Sports Traumatol Arthrosc. 2014;22(12):3163-7.

25. Hudek R, Schmutz S, Regenfelder F, Fuchs B, Koch PP. Novel measurement technique of the tibial slope on conventional MRI. Clin Orthop Relat Res. 2009;467(8):2066-72.

26. Haddad B, Konan S, Mannan K, Scott G. Evaluation of the posterior tibial slope on MR images in different population groups using the tibial proximal anatomical axis. Acta Orthop Belg. 2012;78(6):757-63.

27. Saxena V, Anari JB, Ruutiainen AT, Voleti PB, Stephenson JW, Lee GC. Tibial component considerations in bicruciate-retaining total knee arthroplasty: a 3D MRI evaluation of proximal tibial anatomy. Knee. 2016;23(4):593-9.

28. Zhang Y, Chen Y, Qiang M, Zhang K, Li H, Jiang Y, et al. Comparison between three-dimensional $C T$ and conventional radiography in proximal tibia morphology. Medicine (Baltimore). 2018:97(30):e11632.

29. Amerinatanzi A, Summers R, Ahmadi K, Goel VK, Hewett TE, Nyman E Jr. A novel 3D approach for determination of frontal and coronal plane tibial slopes from MR imaging. Knee. 2017;24(2):207-16.

30. Amerinatanzi A, Summers RK, Ahmadi K, Goel VK, Hewett TE, Nyman E. Automated Measurement of Patient-Specific Tibial Slopes from MRI. Bioengineering (Basel). 2017;4(3):69.

31. Amirtharaj MJ, Hardy BM, Kent RN 3rd, Nawabi DH, Wickiewicz TL Pearle AD, et al. Automated, accurate, and three-dimensional method for calculating sagittal slope of the tibial plateau. J Biomech. 2018;79: 212-7.

32. Ho JPY, Merican AM, Hashim MS, Abbas AA, Chan CK, Mohamad JA. Threedimensional computed tomography analysis of the posterior Tibial slope in 100 knees. J Arthroplast. 2017;32(10):3176-83.

33. Furnstahl P, Vlachopoulos L, Schweizer A, Fucentese SF, Koch PP. Complex osteotomies of Tibial plateau Malunions using computerassisted planning and patient-specific surgical guides. J Orthop Trauma. 2015:29(8):e270-6.

34. Jentzsch T, Vlachopoulos L, Furnstahl P, Muller DA, Fuchs B. Tumor resection at the pelvis using three-dimensional planning and patient-specific instruments: a case series. World J Surg Oncol. 2016; 14(1):249

35. Vlachopoulos L, Schweizer A, Meyer DC, Gerber C, Furnstahl P. Threedimensional corrective osteotomies of complex malunited humeral fractures using patient-specific guides. J Shoulder Elb Surg. 2016;25(12): 2040-7.

36. Schneider P, Eberly DH. Geometric tools for computer graphics. San Francisco: Elsevier science; 2002.

37. Jud L, Roth T, Fürnstahl P, Vlachopoulos L, Sutter R, Fucentese SF. The impact of limb loading and the measurement modality (2D versus 3D) on the measurement of the limb loading dependent lower extremity parameters. BMC Musculoskelet Disord. 2020;21(1):418.

38. Koo TK, Li MY. A guideline of selecting and reporting Intraclass correlation coefficients for reliability research. J Chiropr Med. 2016; 15(2):155-63.

39. Agneskirchner JD, Hurschler C, Wrann CD, Lobenhoffer P. The effects of valgus medial opening wedge high tibial osteotomy on articular cartilage pressure of the knee: a biomechanical study. Arthroscopy. 2007;23(8):852-61.

40. Fukubayashi $\mathrm{T}$, Kurosawa $\mathrm{H}$. The contact area and pressure distribution pattern of the knee. A study of normal and osteoarthrotic knee joints. Acta Orthop Scand. 1980;51(6):871-9.

41. Ihn JC, Kim SJ, Park IH. In vitro study of contact area and pressure distribution in the human knee after partial and total meniscectomy. Int Orthop. 1993;17(4):214-8.
42. Alagic Z, Bujila R, Enocson A, Srivastava S, Koskinen SK. Ultra-low-dose CT for extremities in an acute setting: initial experience with 203 subjects. Skelet Radiol. 2020;49(4):531-9.

43. Jud L, Singh S, Tondelli T, Fürnstahl P, Fucentese SF, Vlachopoulos L. Combined correction of Tibial torsion and Tibial tuberosity-trochlear groove distance by Supratuberositary torsional osteotomy of the tibia. Am J Sports Med. 2020;48(9):2260-7.

\section{Publisher's Note}

Springer Nature remains neutral with regard to jurisdictional claims in published maps and institutional affiliations.
Ready to submit your research? Choose BMC and benefit from:

- fast, convenient online submission

- thorough peer review by experienced researchers in your field

- rapid publication on acceptance

- support for research data, including large and complex data types

- gold Open Access which fosters wider collaboration and increased citations

- maximum visibility for your research: over $100 \mathrm{M}$ website views per year

At BMC, research is always in progress.

Learn more biomedcentral.com/submissions 